\title{
Kinetic Analysis of Poultry Processing Dewatered Sludge (PPDS) Using Thermogravimetric Analysis (TGA)
}

\author{
N.Aniza a , S.Hassan, M.F.M.Nor and M.Fadhil \\ Mechanical Engineering Department, Universiti Teknologi Petronas, Malaysia
}

\begin{abstract}
Kinetic analysis is one of the most important applications in thermal analysis study. In this work, the kinetic analysis of poultry processing dewatered sludge (PPDS) was conducted by using a Thermogravimetric Analysis (TGA) instrument. The kinetic parameters such as activation energy $\left(E_{a}\right)$ and correlation coefficient $\left(R^{2}\right)$ was determined. For this purpose, the non-isothermal thermogravimetric analysis was done in four different heating rates, $\beta=5,10,15$ and $20 \mathrm{~K} / \mathrm{min}$ under oxygen atmosphere. The calculation of kinetic parameters adopted the Flynn-Wall-Ozawa (FWO) and KissingerAkihara-Sunose (KAS) model. The ranges of activation energy of the combustion of the PPDS were 11.81- $51.39 \mathrm{~kJ} / \mathrm{mol}$ and $5.34-42.63 \mathrm{~kJ} / \mathrm{mol}$ respectively.
\end{abstract}

\section{Introduction}

Nowadays, the source of biomass not only limited to agricultural and forestry residue but also in urban waste and animal farming sectors. Poultry processing dewatered sludge (PPDS) is a solid by-product derived by slaughtered poultry from poultry processing industry which can be utilized for energy conversion. PPDS wastewater treatment containing a lot of blood, feather, meat scraps, bone debris, lipid protein, offal etc[1]. Researchers have started paying attention to identify PPDS as potential biomass feedstock to generate electricity due to its viability as well as solving the problem related to environmental issues[2,3].

Biomass can be effectively use as energy by using the thermo chemical conversion process[4]. When introducing new material for biomass feedstock, it is vital to first study the kinetic analysis apart from its fuel characterization. The kinetic parameters are essential as the key in determining reaction mechanism in solid state during the process of combustion or gasification in thermo chemical conversion process[5]. Determination of activation energy $\left(E_{a}\right)$ provides information of the minimum energy required during the combustion process.

Kinetic analysis can be successfully done by thermogravimetric analysis (TGA). Thermogravimetric kinetic analysis of different biomass have been studied extensively by numerous researchers. However, none has attempted to study the kinetic analysis of PPDS via thermogravimetric analysis (TGA) to investigate its potential as a solid fuel for direct combustion process. The aim of this study was to determine the kinetic parameters of non-isothermal combustion of PPDS by TGA approach. The Flynn-Wall-Ozawa and Kissinger-Akihara-Sunose model was applied to calculate the kinetic parameters

\footnotetext{
${ }^{a}$ Corresponding author : noor.aniza87@gmail.com
}

This is an Open Access article distributed under the terms of the Creative Commons Attribution License 2.0, which permits unrestricted use, distribution, and reproduction in any medium, provided the original work is properly cited. 


\section{Materials and methodology}

In this study, sample of PPDS was taken from Dindings Poultry Processing Industry, Sitiawan, Perak. The sample was first dried in an oven at temperature $105^{\circ} \mathrm{C}$ to remove the moisture content. Kinetic analysis of PPDS has been carried out by using the thermogravimetric analyzer (TGA) model LABSYS Evo Setaram. The sample of $10 \mathrm{mg}$ was measured and placed in an alumina crucible. The experiment of non-isothermal TGA was in an oxygen atmosphere condition. The temperature was ramped from $30^{\circ} \mathrm{C}$ to $1000^{\circ} \mathrm{C}$ at four different heating rates, $\beta(5,10,15$ and $20 \mathrm{~K} / \mathrm{min})$. During the process of combustion, the curves of weight loss as a function of time and temperature (TG curve) and weigh loss of sample per unit time against temperature (DTG curve) was recorded continuously by the system.

\subsection{Kinetic Theory}

The Kinetic analysis can be performed either in model fitting method or model free (iso-conversional) method. The fitting models are not as frequently used compared to the iso-conversional methods, which can compute kinetic parameters without prefixing the reaction order. Model free is sufficiently flexible to allow for a change of mechanism during the course of the reaction and mass transfer limitations are reduced by the use of multiple heating rates[6].

Reaction mechanism of biomass can be described as

$$
\text { Biomass } \stackrel{k}{\rightarrow} \text { char }+ \text { volatiles }
$$

where $\mathrm{k}$ is defined as the rate constant of reaction. It can be expressed by the Arrhenius equation as stated in equation (2).

$$
\mathrm{k}=\mathrm{A} e^{-E / R T}
$$

where $E$ is the activation energy $(\mathrm{kJ} / \mathrm{mol}), \mathrm{T}$ is the absolute temperature $(\mathrm{K}), \mathrm{R}$ is the gas constant (8.314 $\left.\mathrm{JK}^{-1} \mathrm{~mol}^{-1}\right)$ and $\mathrm{A}$ is the pre-exponential factor $\left(\mathrm{min}^{-1}\right)$. The rate of heterogeneous solid-state reaction (conversion from solid state to volatile product) is describe by the following equation:

$$
\frac{d \alpha}{d t}=\mathrm{k}(\mathrm{T}) \mathrm{f}(\alpha)
$$

where, $\alpha$, t. $\mathrm{k}(\mathrm{T})$ and $\mathrm{f}(\alpha)$ represent the degree of conversion process, the time, the rate constant and the reaction model respectively. Equation (3) can be converted into conversion (4) obeys from the Arrhenius equation(2).

$$
\frac{d \alpha}{d t}=\mathrm{A} e^{-E / R T} \mathrm{f}(\alpha)
$$

The above equation can be transformed into equation (5) when describing the reaction rates as a function of temperature at a constant heating rate $\left(\beta=\frac{d T}{d t}=\right.$ constant $)$ for non-isothermal state.

$$
\frac{d \alpha}{d T}=\frac{1}{\beta} \mathrm{A} e^{-\frac{E}{R T}} \mathrm{f}(\alpha)
$$

Integrating both side of equation (5) derive the following equation:

$$
\int_{0}^{\alpha} \frac{d \alpha}{f(\alpha)}=\mathrm{g}(\alpha)=\frac{A}{\beta} \int_{T_{0}}^{T} e^{-E / R T} \mathrm{dT}
$$


Iso-conversional methods can be done by varying the heating rates in a series experiments of TGA[7]. In this work, two most common iso-conversional method, the Flynn-Wall-Ozawa (FWO) and Kissinger-Akihara-Sunose (KAS) method was applied to determine the kinetic parameters. Doyle's approximation of $\mathrm{p}(\chi)$ was adopted, which involves measuring the temperature corresponding to the fixed values of $\alpha$ from experiment at different heating rates [8].

For FWO method the equation (7) is applied. The plot of $1 \mathrm{n}(\beta)$ vs. $1000 / \mathrm{T}$ obtained from a series of experiments at several heating rates will give a straight lines. The value of the slope is equal to $1.052 \mathrm{E} / \mathrm{R}$ which is beneficial to calculate the activation energy. The KAS method is according to the (8) expression where the activation energy can be obtained by plotting the $\ln \left(\beta / T^{2}\right)$ vs. 1000/T. The slope is equal to $-\mathrm{E} / \mathrm{R}$.

$$
\begin{gathered}
\ln (\beta)=\ln \left[\frac{A E}{R g(\alpha)}\right]-5.331-1.052 \frac{E}{R T} \\
\ln \left(\frac{\beta}{T^{2}}\right)=\ln \left(\frac{A R}{E g \alpha}\right)-\frac{E}{R T}
\end{gathered}
$$

\section{Result and discussion}

\subsection{TGA Result}

The TG and DTG result obtained from the combustion process of PPDS in TGA were carried out in four different heating rates as shown in Figure 1. and Figure 2. As can be seen from the curves, three region of decomposition process can be detected through the starts and ends points of DTG curves. Each peak in DTG describes the degradation of biomass at every stage during the combustion process The initial loss of weight at $30^{\circ} \mathrm{C}$ to $200^{\circ} \mathrm{C}$ in the first region was due to the evaporation of moisture. The second region was attributed to the release of volatile process from $200^{\circ} \mathrm{C}$ to $450^{\circ} \mathrm{C}$. Sudden drop of weight happened in the third region at temperature between $450^{\circ} \mathrm{C}$ to $500^{\circ} \mathrm{C}$ corresponding to combustion of char. Once the fuel content of the PPDS deplete, the mass correspoding to the ashes become constant[8]. As observed, heating rates have significant effect on the thermal behavior of PPDS. With the increment of heating rates, the curves latterally shift to the right. This result is due to the fact that with the addition of heating rates, thermal degradation delayed, heat transfer to the particle of sample acquired in short time thus peak temperature shifted to the higher value[9].

\subsection{Kinetic analysis}

In this study, data from TG curves have been used in order to plot the curves of fitting to kinetic model propose by Flynn-Wall-Ozawa (FWO) and Kissinger-Akihara-Sunose (KAS). TG curves of four different heating rates, $\beta$ from TGA are used to allow the calculation of kinetic parameters of non-isothermal model free method. Several conversion degrees, $\alpha$ of each TG curves have been pointed out $(10 \%, 20 \%, 30 \%, 40 \%, 50 \%, 60 \%)$ and the corresponding temperature has been found. The plotted graph for kinetic calculation adopted FWO and KAS model are shown in Figure 3. and Figure 4 . The apparent activation energy, $E_{a}$ at each conversion was obtained from the slope. 


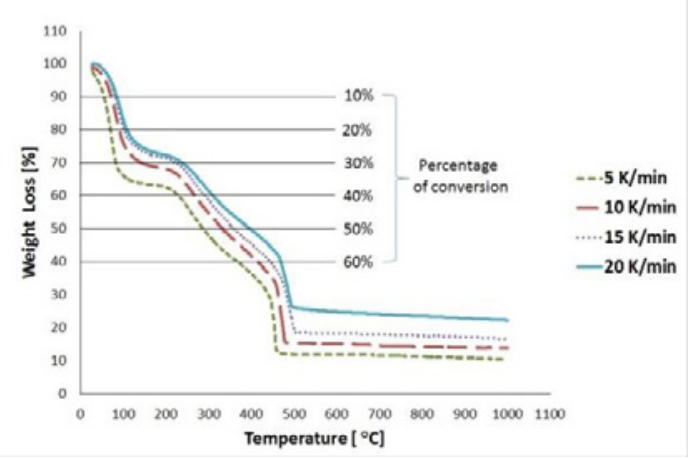

Figure 1. TG curves of PPDS in oxygen at four different heating rates

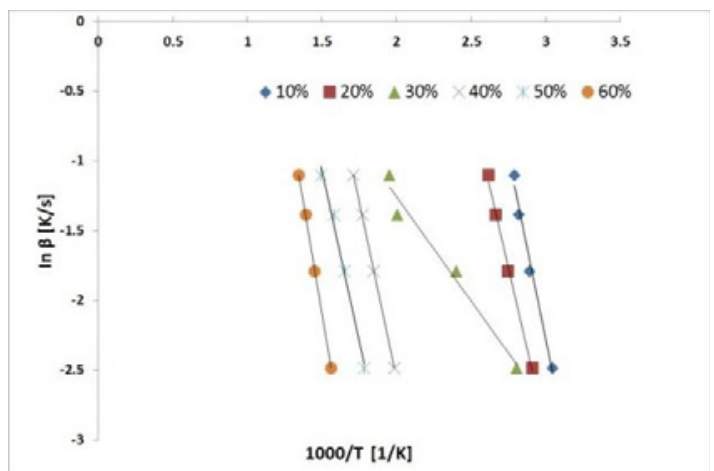

Figure 3. FWO plot of PPDS for different percent of conversion

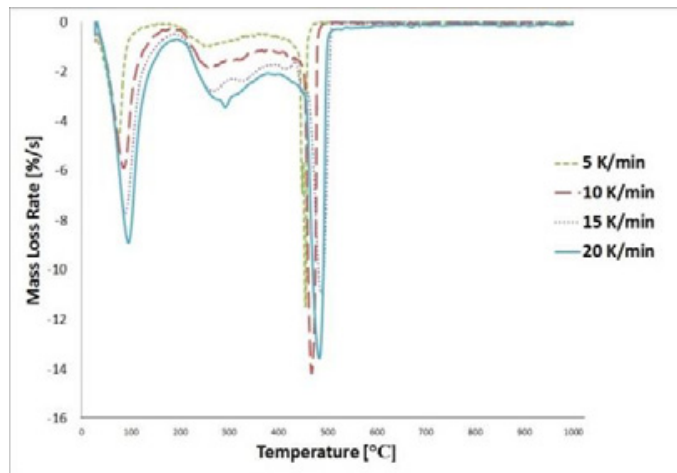

Figure 2. DTG curves of PPDS in oxygen at four different heating rates

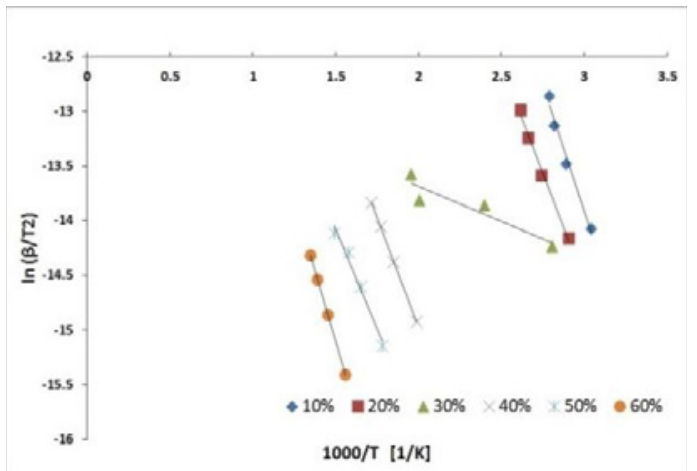

Figure 4. KAS plot of PPDS for different percent of conversion

Table 1. Kinetic parameters of PPDS for Flynn-Wall-Ozawa (FWO) model and Kissinger-Akahira-Sunose (KAS) model.

\begin{tabular}{cccc|ccc}
\hline \multicolumn{3}{l}{ FWO model } & & \multicolumn{3}{l}{ KAS model } \\
\hline $\boldsymbol{\alpha}$ & Slope & $E_{a}(\mathrm{~kJ} / \mathrm{mol})$ & $R^{2}$ & Slope & $E_{a}(\mathrm{~kJ} / \mathrm{mol})$ & $R^{2}$ \\
& & & & & & \\
$\mathbf{1 0} \%$ & -5.271 & 41.66 & 0.987 & -4.586 & 38.12 & 0.983 \\
$\mathbf{2 0} \%$ & -4.659 & 36.82 & 0.994 & -3.936 & 32.72 & 0.992 \\
$\mathbf{3 0} \%$ & -1.494 & 11.81 & 0.974 & -0.642 & 5.34 & 0.867 \\
$\mathbf{4 0} \%$ & -5.083 & 40.17 & 0.999 & -4.003 & 33.28 & 0.999 \\
$\mathbf{5 0} \%$ & -4.867 & 38.46 & 0.989 & -3.645 & 30.30 & 0.979 \\
$\mathbf{6 0} \%$ & -6.502 & 51.39 & 0.999 & -5.127 & 42.63 & 0.999 \\
\hline
\end{tabular}

The results of kinetic parameters of PPDS are summarized in Table. 1. The activation energy of PPDS for each corresponding percentage of conversion, $\alpha$ for both FWO and KAS models shows different values. For FWO model, activation energy is range between $11.81-51.39 \mathrm{~kJ} / \mathrm{mol}$, while for KAS model range between 5.34- $42.63 \mathrm{~kJ} / \mathrm{mol}$. The value of activation energy $\mathrm{E}_{\mathrm{a}}$ depends on the slope of the linear fitting plotted above, as the $E_{a}$ calculation was based on the linear equation. The linear regression for $\alpha=30 \%$ for both model shows high inclination resulting the lowest activation energy. At this phase, weight of PPDS during combustion was 30\% loss, the first region which equal to absorption of moisture content was about to finished and value of activation energy drop drastically. 
This can be confirmed by the TG curve in Figure 1. at temperature between $30^{\circ} \mathrm{C}-200^{\circ} \mathrm{C}$ for every heating rates. The activation energy started to increase at $40 \%$ of conversion $\left(E_{a}=40.17\right.$ and 33.28 $\mathrm{kJ} / \mathrm{mol}$ for FWO and KAS method respectively). This stage is corresponding to the initial point of devolatilization process of PPDS where the combustion process requires more energy to start releasing the volatile matter. The highest value of activation energy was at the stage of $60 \%$ conversion where the weight loss is peak ( $\mathrm{T}$ range between $450^{\circ} \mathrm{C}-500^{\circ} \mathrm{C}$ ) and requires maximum activation energy to complete the combustion process of char $\left(E_{a}=51.39\right.$ and $42.63 \mathrm{~kJ} / \mathrm{mol}$ for FWO and KAS method respectively).

\section{Conclusion}

The result of TGA done in this experiment shows good agreement with the result discussed in literature. The activation energy at various conversion of degree reveal different amount of activation energy proved that energy required at each stage was due to the reaction mechanism occurred during the decomposition process. The kinetic data obtained in this study are beneficial for modeling and designing the thermo-chemical conversion system for PPDS biomass.

\section{References}

1. A. Hassan, S. Aris, A. Abdalla, and N. Aniza, "The Prospects of Electricity Generation From Poultry Processing Dewatered Sludge (PPDS) In Malaysia."

2. A. B. A. Ibrahim, M. S. Aris, and Y. S. Chin, "Development of Fuel Briquettes from Dewatered Poultry Sludge," International Conference on Future Electrical Power and Energy Systems vol. 9, pp. 469-476, (2012)

3. A.H. Hassan, A.B.A. Ibrahim, M.F.H.A. Muttalib, and M.S. Aris, "Fuel Characterization and Energy Prediction of Malaysian Poultry Processing," Asean Journal of Scientific Research 6 (3), pp. 498-507, (2013).

4. A. Demirbas, "Combustion characteristics of different biomass fuels," Prog. Energy Combust. Sci., vol. 30, no. 2, pp. 219-230, (2004)

5. M. Otero, X. Gómez, a I. García, and a Morán, "Effects of sewage sludge blending on the coal combustion: a thermogravimetric assessment.," Chemosphere, vol. 69, no. 11, pp. 1740-50, Nov. (2007)

6. C. Gai, Y. Dong, and T. Zhang, "The kinetic analysis of the pyrolysis of agricultural residue under non-isothermal conditions.," Bioresour. Technol., vol. 127, pp. 298-305, Jan. (2013)

7. A. Khawam and D. R. Flanagan, "Role of isoconversional methods in varying activation energies of solid-state kinetics," Thermochim. Acta, vol. 436, no. 1-2, pp. 101-112, Oct. (2005)

8. M. Otero, M. E. Sanchez, X. Gómez, and A. Morán, "Thermogravimetric analysis of biowastes during combustion.," Waste Manag., vol. 30, no. 7, pp. 1183-7, Jul. (2010)

9. E. Biagini, A. Fantei, and L. Tognotti, "Effect of the heating rate on the devolatilization of biomass residues," Thermochim. Acta, vol. 472, no. 1-2, pp. 55-63, Jun. (2008) 